International Journal of Systems Signal Control and Engineering Application 5 (1): 14-20, 2012

ISSN: $1997-5422$

(C) Medwell Journals, 2012

\title{
H-Infinity Controller with LMI Region Schemes for a Lab-Scale Rotary Pendulum Crane System
}

\author{
M.Z. Mohd Tumari, M.S. Saealal, Y. Abdul Wahab and M.R. Ghazali \\ Faculty of Electrical and Electronics Engineering, Universiti Malaysia Pahang, \\ 26600 Pekan, Pahang, Malaysia
}

\begin{abstract}
This study presents an H-infinity controller with LMI region schemes for a lab-scale rotary pendulum crane system. H-infinity synthesis with pole clustering schemes is used to control the hub angle of the arm of rotary pendulum crane system with very minimal sway angle. The performance of the lab-scale rotary pendulum crane system is examined in terms of time response specifications of hub angle of the arm, minimal sway angle of pendulum and minimal control input. To examine the effectiveness of the proposed controller, it is compared with LQR controller schemes. The implementation results show that H-infinity controller with confined closed-loop poles based on LMI region produce a fast tracking capability with very minimal sway and control input.
\end{abstract}

Key words: Rotary pendulum crane, sway control, trajectory tracking, LMI region, H-infinity controller, Malaysia

\section{INTRODUCTION}

Recently, research in controlling rotary pendulum crane system can be categorized into open and closedloop control system. For example, input shaping strategy was applied to the crane system by many researchers (Ahmad et al., 2009a, 2010a; Blackburn et al., 2010). This scheme has been proven to be the best method in reducing the vibration and sway of any flexible structures (Vaughan et al., 2010; Ahmad et al., 2009b). Since, input shaping strategy is sensitive to the system parameters and could not compensate for the effect of wind disturbance, they obtained a poor performance results. On the other hand, feedback control which is well known to be less sensitive to disturbances and parameter variations (Belanger, 1995) is also adopted for controlling the rotary pendulum crane system. Recent research on controlling this type of crane system was presented by Ahmad et al. (2010b). The researcher had proposed Proportional Derivative (PD) controllers for position control and non-collocated PID controller for anti-swing control. Furthermore, the same researcher also has proposed a fuzzy logic controller for anti-swing control of rotary crane system (Ahmad et al., 2011). The proposed fuzzy logic controller is designed based on the behaviour of sway motion of pendulum. Besides that a specific study on actively control the sway motion of rotary pendulum due to disturbance effect was proposed by Ahmad et al. (2010c). They proposed a comparative assessment study between optimal and intelligent control. However, all the previous mentioned literature does not consider in detail the desired location of poles in achieving a fast trajectory tracking of rotary pendulum crane with very minimal sway motion. In this study, H-infinity synthesis with pole clustering based on LMI Techniques is used to control the hub angle of the arm of rotary pendulum crane with very minimal sway. In order to design the controller, the linear model of rotary pendulum crane system as shown in Fig. 1 .

The reason for choosing $\mathrm{H}$-infinity synthesis is because of its good performance in handling with various types of control objectives such as disturbance cancellation, robust stabilization of uncertain systems, input tracking capability or shaping of the open-loop response. Nevertheless, the weakness of $\mathrm{H}$-infinity controller is in handling with transient response behavior and closed-loop pole location instead of frequency aspects (Chilali and Gahinet, 1996). As we all know, a good time response specifications and closed-loop damping of rotary pendulum crane system can be achieved by forcing the closed-loop poles to the left-half plane. Moreover, many literatures have proved that $\mathrm{H}$-infinity synthesis can be formulated as a convex optimization problem involving Linear Matrix Inequalities (LMI) (Gahinet and Apkarian, 1993; Iwasaki and Skelton, 1994; Packard, 1994). In this case, the normal Riccati

Corresponding Author: M.Z. Mohd Tumari, Faculty of Electrical and Electronics Engineering, Universiti Malaysia Pahang, 26600 Pekan, Pahang, Malaysia 


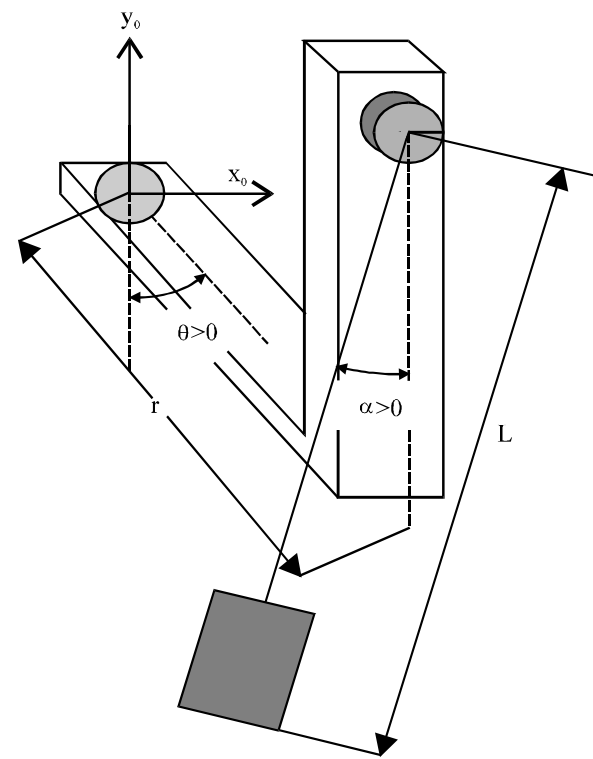

Fig. 1: Description of the rotary crane system

equation with inequality condition was used. This behavior will give wide range of flexibility in combining several constraints on the closed loop system. This flexible nature of LMI schemes can be used to handle $\mathrm{H}$-infinity controller with pole placement constraints. In this research, the pole placement constraints will refer directly to regional pole placement (Chilali et al., 1999). It is slightly difference with point-wise pole placement where poles are assigned to specific locations in the complex plane based on specific desired time response specifications. In this case, the closed-loop poles of rotary pendulum crane system are confined in a suitable region of the complex plane. This region consists of wide variety of useful clustering area such as half-planes, disks, sectors, vertical/horizontal strips and any intersection thereof (Chilali et al., 1999). Using LMI approach, the regional pole placement known as LMI region combined with design objective in $\mathrm{H}$-infinity controller should guarantee a fast input tracking capability, precise hub angle of the arm positioning and very minimal sway motion.

\section{MATERIALS AND METHODS}

The 2-DOF rotary pendulum crane system with its payload considered in this research is shown in Fig. 1 where $\theta$ and $\alpha$ denote the horizontal angle of the arm and the sway angle of the pendulum, respectively, $\mathrm{r}$ and $\mathrm{L}$ is the length of arm and pendulum. In this research, the pendulum and payload can be considered as point masses. The lab-scale rotary crane system is shown in

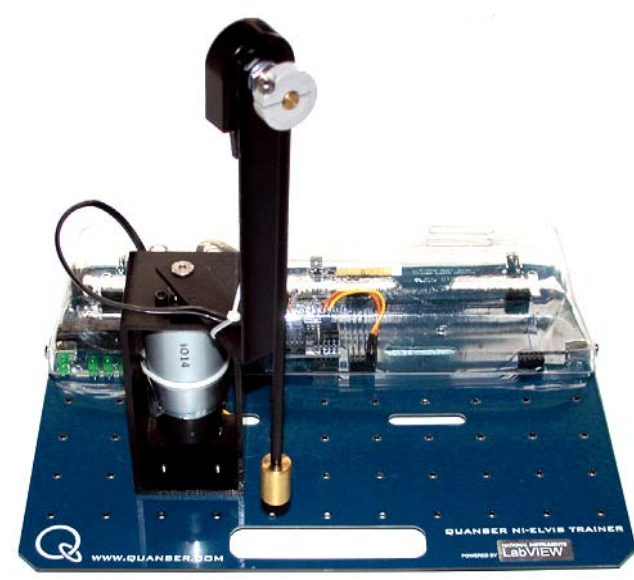

Fig. 2: Lab-scale rotary crane system

Fig. 2. This study also provides a brief description on the modeling of the rotary crane system as a basis of a simulation environment for development and assessment of the proposed control techniques. The Euler-Lagrange formulation is considered in characterizing the dynamic behavior of the crane system incorporating payload. Considering the motion of the rotary pendulum crane on a horizontal plane, the kinetic energy of the system can thus be formulated as:

$$
\begin{aligned}
\mathrm{T}= & \frac{1}{2} \mathrm{~J}_{\mathrm{a}} \dot{\theta}^{2}+\frac{1}{2} \mathrm{~m}(\mathrm{~L} \cos \alpha(\dot{\alpha})+\mathrm{r} \dot{\theta})^{2}+ \\
& \frac{1}{2} \mathrm{~m}(\mathrm{~L} \sin \alpha(\dot{\alpha}))^{2}+\frac{1}{2} \mathrm{~J}_{\mathrm{p}} \dot{\alpha}^{2}
\end{aligned}
$$

The potential energy of the beam can be formulated as

$$
\mathrm{U}=\operatorname{mgl}(1-\cos \alpha)
$$

To obtain a closed-form dynamic model of the rotary pendulum crane, the energy expressions in Eq. 1 and 2 are used to formulate the Lagrangian $\mathrm{L}=\mathrm{T}-\mathrm{U}$. Let the generalized torques corresponding to the generalized state variables $\overline{\mathrm{q}}=\{\theta, \alpha\}$ be $\bar{\tau}=\{\tau, 0\}$. Using Lagrangian's equation:

$$
\begin{aligned}
& \frac{\mathrm{d}}{\mathrm{dt}}\left(\frac{\partial \mathrm{L}}{\partial \dot{\theta}}\right)-\frac{\partial \mathrm{L}}{\partial \theta}=\tau-\mathrm{B} \dot{\theta} \\
& \frac{\mathrm{d}}{\mathrm{dt}}\left(\frac{\partial \mathrm{L}}{\partial \dot{\alpha}}\right)-\frac{\partial \mathrm{L}}{\partial \alpha}=0
\end{aligned}
$$

and linearizing $\alpha=0$, the equation of motion is obtained as:

$$
\left(\mathrm{J}_{\mathrm{a}}+\mathrm{mr}^{2}\right) \ddot{\theta}+\mathrm{mLr} \ddot{\alpha}=\tau-\mathrm{B} \dot{\theta}
$$




$$
\frac{4}{3} \mathrm{~mL}^{2} \ddot{\alpha}+\mathrm{mLr} \ddot{\theta}+\mathrm{mgL} \alpha=0
$$

Where:

$\mathrm{m}=$ The centre of mass of pendulum and payload

$\mathrm{B}=$ The arm viscous damping

$\mathrm{J}_{\mathrm{a}}=$ The moment of inertia of the arm

$\mathrm{J}_{\mathrm{p}}=$ The moment of inertia of the pendulum

$\mathrm{g}=$ The gravity effect

In this study, the values of the parameters are defined as $\mathrm{m}=0.027 \mathrm{~kg}, \mathrm{~J}_{\mathrm{a}}=1.23 \times 10^{-4} \mathrm{~kg} \mathrm{~m}^{2}, \mathrm{~L}=0.191 \mathrm{~m}$, $\mathrm{r}=0.06668, \mathrm{~B}=0.001 \mathrm{Nm} / \mathrm{rad} / \mathrm{sec}, \mathrm{g}=9.81 \mathrm{~m} \mathrm{sec}^{-2}$. Then, the state-space representation of rotary pendulum crane system can be expressed as:

$$
\begin{aligned}
& \dot{x}=A x+B u \\
& y=C x
\end{aligned}
$$

with the vector $\mathrm{x}=[\theta \alpha \dot{\theta} \dot{\alpha}]^{\mathrm{T}}$ and the matrices $\mathrm{A}-\mathrm{C}$ are given by:

$$
\begin{aligned}
A & =\left[\begin{array}{cccc}
0 & 0 & 1 & 0 \\
0 & 0 & 0 & 1 \\
0 & 86.6 & -6.54 & 0 \\
0 & -61.2 & 1.71 & 0
\end{array}\right], \mathrm{B}=\left[\begin{array}{llll}
0 & 0 & 6544 & -1711
\end{array}\right] \\
\mathrm{C} & =\left[\begin{array}{llll}
1 & 0 & 0 & 0
\end{array}\right]
\end{aligned}
$$

In this study, an integral state feedback control is used as a platform to design the proposed controller. The block diagram of integral state feedback control is shown in Fig. 3.

The main objective of the proposed controller is to find the gain parameter matrix, $\mathrm{F}$ and $\mathrm{G}$ such that it fulfills the design requirement. From the block diagram of Fig. 3, the control input of the system is derived as:

$$
\mathrm{u}(\mathrm{t})=\mathrm{Fx}(\mathrm{t})+\mathrm{Gv}(\mathrm{t})
$$

Where:

$$
v(t)=\int_{0}^{t} e(\tau) d \tau
$$

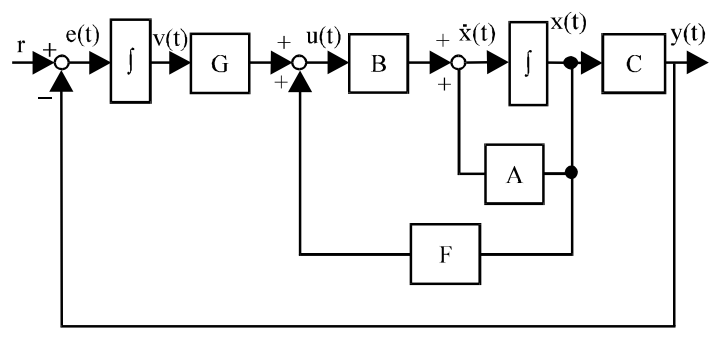

Fig. 3: Block diagram of integral state feedback control
And:

$$
e(t)=r-y(t)
$$

Using new state variable $x_{e}=\left[\begin{array}{ll}x^{\mathrm{T}} & \mathrm{v}\end{array}\right]^{\mathrm{T}}$ and Eq. 8, the representation of state space equation can be rewrite as:

$$
\begin{aligned}
& {\left[\begin{array}{l}
\dot{x}(t) \\
\dot{v}(t)
\end{array}\right]=\left[\begin{array}{cc}
\mathrm{A} & 0 \\
-\mathrm{C} & 0
\end{array}\right]\left[\begin{array}{l}
\mathrm{x}(\mathrm{t}) \\
\mathrm{v}(\mathrm{t})
\end{array}\right]+\left[\begin{array}{l}
\mathrm{B} \\
0
\end{array}\right] \mathrm{u}(\mathrm{t})+\left[\begin{array}{l}
0 \\
1
\end{array}\right]} \\
& \mathrm{e}(\mathrm{t})=\mathrm{r}-\mathrm{Cx}(\mathrm{t})
\end{aligned}
$$

Next, at the steady state condition as $t \rightarrow \infty$, the state space equation can be written in the following form:

$$
\begin{aligned}
& {\left[\begin{array}{l}
0 \\
0
\end{array}\right]=\left[\begin{array}{cc}
\mathrm{A} & 0 \\
-\mathrm{C} & 0
\end{array}\right]\left[\begin{array}{l}
\mathrm{x}(\infty) \\
\mathrm{v}(\infty)
\end{array}\right]+\left[\begin{array}{l}
\mathrm{B} \\
0
\end{array}\right] \mathrm{u}(\infty)+\left[\begin{array}{l}
0 \\
1
\end{array}\right]} \\
& 0=\mathrm{r}-\mathrm{Cx}(\infty)
\end{aligned}
$$

By subtracting Eq. 9-10, the state space form is converted to:

$$
\begin{aligned}
& \dot{\tilde{\mathrm{x}}}_{\mathrm{e}} \mathrm{t}=\tilde{\mathrm{A}}_{\mathrm{x}}(\mathrm{t})+\tilde{\mathrm{B}}_{2} \tilde{\mathrm{u}}(\mathrm{t}) \\
& \tilde{\mathrm{e}}(\mathrm{t})=\tilde{\mathrm{C}}_{1} \tilde{\mathrm{x}}_{\mathrm{e}}(\mathrm{t})
\end{aligned}
$$

Where:

$$
\begin{aligned}
& \tilde{\mathrm{A}}=\left[\begin{array}{cc}
\mathrm{A} & 0 \\
-\mathrm{C} & 0
\end{array}\right], \tilde{\mathrm{B}}_{2}=\left[\begin{array}{l}
\mathrm{B} \\
0
\end{array}\right], \tilde{\mathrm{x}}_{\mathrm{e}}=\left[\begin{array}{l}
\tilde{\mathrm{x}} \\
\tilde{\mathrm{v}}
\end{array}\right]=\left[\begin{array}{l}
\mathrm{x}-\mathrm{x}(\infty) \\
\mathrm{v}-\mathrm{v}(\infty)
\end{array}\right] \\
& \tilde{\mathrm{C}}_{1}=\left[\begin{array}{ll}
-\mathrm{C} & 0
\end{array}\right], \tilde{\mathrm{e}}(\mathrm{t})=\mathrm{e}-\mathrm{e}(\infty)
\end{aligned}
$$

Then, the new control input function is described as:

$$
\tilde{u}(t)=F \tilde{x}(t)+G \tilde{v}(t)=K \tilde{x}_{e}(t)
$$

Finally, a closed-loop state space equation with controller gain, $\mathrm{K}$ can be obtained:

$$
\begin{aligned}
& \dot{\tilde{\mathrm{x}}}_{\mathrm{e}}(\mathrm{t})=\tilde{\mathrm{A}}_{\mathrm{d}} \tilde{\mathrm{x}}_{\mathrm{e}}(\mathrm{t})+\tilde{\mathrm{B}}_{1} \mathrm{w} \\
& \tilde{\mathrm{y}}(\mathrm{t})=\tilde{\mathrm{C}}_{1} \tilde{\mathrm{x}}_{\mathrm{e}}(\mathrm{t})+\tilde{\mathrm{D}}_{11} \mathrm{w}+\tilde{\mathrm{D}}_{12} \mathrm{u}
\end{aligned}
$$

Where:

$$
\tilde{\mathrm{A}}_{\mathrm{cl}}=\left(\tilde{\mathrm{A}}+\widetilde{\mathrm{B}}_{2} \mathrm{~K}\right), \widetilde{\mathrm{B}}_{1}=\left[\begin{array}{lllll}
0 & 0 & 0 & 0 & -1
\end{array}\right], \widetilde{\mathrm{D}}_{11}=1, \widetilde{\mathrm{D}}_{12}=0
$$

and $\mathrm{w}$ is exogenous input disturbance or reference input to the system. Let $\mathrm{G}_{\mathrm{yw}}(\mathrm{s})$ denote the closed loop transfer function from $\mathrm{w}$ to $\mathrm{y}$ under state feedback control $\mathrm{u}=\mathrm{Kx}$. Then, for a prescribed closed-loop $\mathrm{H}$-infinity performance $\gamma>0$, the constrained $\mathrm{H}_{\infty}$ problem consists of finding a state feedback gain $\mathrm{K}$ that fulfil the following objectives: 
- The closed-loop poles are required to lie in some LMI stability region $\mathrm{D}$ contained in the left-half plane

- Guarantees the $\mathrm{H}_{\infty}$ performance $\left\|\mathrm{G}_{\mathrm{yw}}\right\|_{\infty}<\gamma$

Quote from the definition in Chilali and Gahinet (1996), a subset D of the complex plane is called an LMI region if there exist a symmetric matrix $\alpha \in \mathrm{R}^{\mathrm{m} \times \mathrm{m}}$ and a matrix $\beta \in \mathrm{R}^{\mathrm{m} \times \mathrm{m}}$ such that:

$$
\mathrm{D}=\left\{\mathrm{z} \in \mathrm{C}: \mathrm{f}_{\mathrm{D}}(\mathrm{z})<0\right\}
$$

Where:

$$
f_{D}(z):=\alpha+z \beta+\bar{z} \beta^{T}
$$

Then, pole location in a given LMI region can be characterized in terms of the $m \times m$ block matrix:

$$
M_{D}\left(\tilde{A}_{c l}, X_{D}\right):=\alpha \otimes X_{D}+\beta \otimes\left(\tilde{A}_{d l} X_{D}\right)+\beta^{T} \otimes\left(\tilde{A}_{d l} X_{D}\right)^{T}
$$

Quote from the theorem in Chilali and Gahinet (1996), the matrixis $\tilde{A}_{\mathrm{cl}} \mathrm{D}$-stable if and only if there exists a symmetric matrix $\mathrm{X}$ such that:

$$
\mathrm{M}_{\mathrm{D}}\left(\tilde{\mathrm{A}}_{\mathrm{cl}}, \mathrm{X}_{\mathrm{D}}\right)<0, \mathrm{X}_{\mathrm{D}}>0
$$

In this study, the region $S(\lambda, r, \theta)$ of complex numbers $\mathrm{x}+\mathrm{jy}$ such that:

$$
\mathrm{x}<-\lambda<0,|\mathrm{x}+\mathrm{jy}|<\mathrm{r}, \tan \theta \mathrm{x}<-|\mathrm{y}|
$$

as shown in Fig. 4. The advantages of placing the closed-loop poles to this region are the cart position response ensures a minimum decay rate $\lambda$, a minimum damping ratio $\xi_{0}=\cos \theta$ and a maximum undamped natural frequency $\omega_{\mathrm{d}}=\mathrm{r} \sin \theta$ (Chilali and Gahinet, 1996).

Equation 18-20 show the clustering region used in this study which are $\lambda$ stability region, a disk and the conic sector, respectively:

$$
\begin{gathered}
M_{D 1}\left(\tilde{A}_{\mathrm{c}}, \mathrm{X}_{\mathrm{D} 1}\right):=\tilde{\mathrm{A}}_{\mathrm{d}} \mathrm{X}_{\mathrm{D} 1}+\mathrm{X}_{\mathrm{D} 1} \tilde{\mathrm{A}}_{\mathrm{cl}}^{\mathrm{T}}+2 \lambda \mathrm{X}_{\mathrm{D} 1}<0 \\
\mathrm{M}_{\mathrm{D} 2}\left(\tilde{\mathrm{A}}_{\mathrm{cl}}, \mathrm{X}_{\mathrm{D} 2}\right):=\left(\begin{array}{cc}
-\mathrm{r} \mathrm{X}_{\mathrm{D} 2} & \tilde{\mathrm{A}}_{\mathrm{cl}} \mathrm{X}_{\mathrm{D} 2} \\
\mathrm{X}_{\mathrm{D} 2} \tilde{\mathrm{A}}_{\mathrm{d}}^{\mathrm{T}} & -\mathrm{r} \mathrm{X}_{\mathrm{D} 2}
\end{array}\right)<0 \\
\mathrm{M}_{\mathrm{D} 3}\left(\tilde{\mathrm{A}}_{\mathrm{cl}}, \mathrm{X}_{\mathrm{D} 3}\right):= \\
\left(\begin{array}{cc}
\sin \theta\left(\tilde{\mathrm{A}}_{\mathrm{cl}} \mathrm{X}_{\mathrm{D} 3}+\tilde{\mathrm{A}}_{\mathrm{cl}} \mathrm{X}_{\mathrm{D} 3}^{\mathrm{T}}\right) & \cos \theta\left(\tilde{\mathrm{A}}_{\mathrm{c}} \mathrm{X}_{\mathrm{D} 3}-\tilde{\mathrm{A}}_{\mathrm{cl}} \mathrm{X}_{\mathrm{D} 3}^{\mathrm{T}}\right) \\
\cos \theta\left(\mathrm{X}_{\mathrm{D} 3} \tilde{\mathrm{A}}_{\mathrm{cl}}^{\mathrm{T}}-\tilde{\mathrm{A}}_{\mathrm{d}} \mathrm{X}_{\mathrm{D} 3}\right) & \sin \theta\left(\tilde{\mathrm{A}}_{\mathrm{d}} \mathrm{X}_{\mathrm{D} 3}+\tilde{\mathrm{A}}_{\mathrm{cl}} \mathrm{X}_{\mathrm{D} 3}^{\mathrm{T}}\right)
\end{array}\right)<0
\end{gathered}
$$

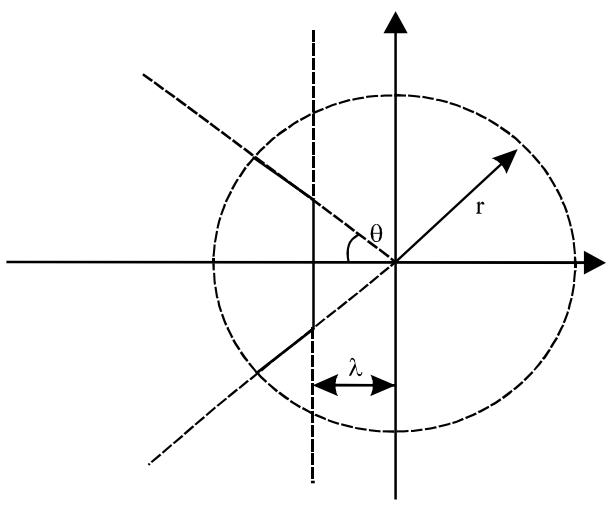

Fig. 4: Region $S(\lambda, r, \theta)$

where this region is the intersection of three elementary LMI regions:

$$
\left(\mathrm{M}_{\mathrm{D} 1 \cap \mathrm{D} 2 \cap \mathrm{D} 3}\left(\tilde{\mathrm{A}}_{\mathrm{d}}, \mathrm{X}_{\mathrm{D}}\right)\right)
$$

Meanwhile, the $\mathrm{H}_{\infty}$ constraint is equivalent to the existence of a solution $\mathrm{X}_{\infty}>0$ to the LMI:

$$
\left(\begin{array}{ccc}
\tilde{\mathrm{A}}_{\mathrm{cl}} \mathrm{X}_{\infty}+\mathrm{X}_{\infty} \tilde{\mathrm{A}}_{\mathrm{d}}^{\mathrm{T}} & \mathrm{X}_{\infty} \tilde{\mathrm{C}}_{1}^{\mathrm{T}} & \tilde{\mathrm{B}}_{1} \\
\tilde{\mathrm{C}}_{1} \mathrm{X}_{\infty} & -\gamma \mathrm{I} & \tilde{\mathrm{D}}_{11} \\
\tilde{\mathrm{B}}_{1}^{\mathrm{T}} & \tilde{\mathrm{D}}_{11}^{\mathrm{T}} & -\gamma \mathrm{I}
\end{array}\right)<0
$$

Equation 21 is also known as the Bounded Real Lemma (Boyd et al., 1994). As described before, the main objective of this study is to minimize the $\mathrm{H}_{\infty}$ norm of $\mathrm{G}_{\mathrm{yw}}(\mathrm{s})$ over all state feedback gains $\mathrm{K}$ that enforce the pole constraints. However, this problem is not jointly convex in the variables $X_{D 1}-X_{D 3}, X_{\infty}$ and $K$. The convexity can be enforced by seeking a common solution:

$$
\mathrm{X}=\mathrm{X}_{\mathrm{D} 1}=\mathrm{X}_{\mathrm{D} 2}=\mathrm{X}_{\mathrm{D} 3}=\mathrm{X}_{\infty}>0
$$

to Eq. 18-21 and rewriting these equations using the auxiliary variable $\mathrm{Y}=\mathrm{KX}$. These changes of variables lead to the suboptimal LMI approach to $\mathrm{H}$-infinity synthesis with pole assignment in LMI regions. As a result, the new representations of Eq. 18-21 are shown in Eq. 23-26:

$$
\begin{gathered}
\operatorname{Herm}\left[\tilde{\mathrm{A} X}+\tilde{\mathrm{B}}_{2} \mathrm{Y}\right]+2 \lambda \mathrm{X}<0 \\
\left(\begin{array}{cc}
-\mathrm{rX} & \tilde{\mathrm{A}} \mathrm{X}+\tilde{\mathrm{B}}_{2} \mathrm{Y} \\
* & -\mathrm{rX}
\end{array}\right)<0 \\
\left(\begin{array}{cc}
\sin \theta\left(\operatorname{Herm}\left[\tilde{\mathrm{A} X}+\tilde{\mathrm{B}}_{2} \mathrm{Y}\right]\right) & \cos \theta\left(\operatorname{Herm}\left[\tilde{\mathrm{A} X}-\tilde{\mathrm{B}}_{2} \mathrm{Y}\right]\right) \\
* & \sin \theta\left(\operatorname{Herm}\left[\tilde{\mathrm{A} X}+\tilde{\mathrm{B}}_{2} \mathrm{Y}\right]\right)
\end{array}\right)<0
\end{gathered}
$$


Where:

$$
\left(\begin{array}{ccc}
\operatorname{Herm}\left[\tilde{\mathrm{A} X}+\tilde{\mathrm{B}}_{2} \mathrm{Y}\right] & \mathrm{X} \tilde{\mathrm{C}}_{1}^{\mathrm{T}} & \tilde{\mathrm{B}}_{1} \\
* & -\gamma \mathrm{I} & \tilde{\mathrm{D}}_{11} \\
* & * & -\gamma \mathrm{I}
\end{array}\right)<0
$$

$$
\operatorname{Herm}\left[\tilde{\mathrm{A} X}+\tilde{\mathrm{B}}_{2} \mathrm{Y}\right]=\tilde{\mathrm{A}} \mathrm{X}+\tilde{\mathrm{B}}_{2} \mathrm{Y}+\tilde{\mathrm{X}} \mathrm{A}^{\mathrm{T}}+\mathrm{Y} \tilde{\mathrm{B}}_{2}^{\mathrm{T}}
$$

and $*$ is an ellipsis for terms induced by symmetry (Chilali et al., 1999). In this study, the entire LMI problem is solved using well known LMI optimization software which is LMI control toolbox.

To evaluate the effectiveness of the proposed controller, the results of this study is compared with linear quadratic regulator controller. In order to design the $\mathrm{LQR}$ controller, a linear state-space model of the rotary crane system in Eq. 6 is utilized. The technique involves choosing a control law $\mathrm{u}=\psi(\mathrm{x})$ which stabilizes the origin (i.e., regulates $\mathrm{x}$ to zero) while minimizing the quadratic cost function:

$$
J=\int_{0}^{\infty} x(t)^{T} Q x(t)+u(t)^{T} R u(t) d t
$$

Where, $\mathrm{Q}=\mathrm{Q}^{\mathrm{T}} \geq 0$ and $\mathrm{R}=\mathrm{R}^{\mathrm{T}}>0$. The matrices $\mathrm{Q}$ and $\mathrm{R}$ are called the state and control penalty matrices, respectively. If the components of $\mathrm{Q}$ are chosen large relative to those of $\mathrm{R}$ then deviations of $\mathrm{x}$ from zero will be penalized heavily relative to deviations of $u$ from zero. On the other hand if the components of $\mathrm{R}$ are large relative to those of Q then control effort will be more costly and the state will not converge to zero as quickly. A famous and somewhat surprising result due to Kalman is that the control law which minimizes $\mathrm{J}$ always takes the form $\mathrm{u}=\psi(\mathrm{x})=-\mathrm{K}_{\mathrm{LQR}} \mathrm{X}$. The optimal regulator for a LTI System with respect to the quadratic cost function above is always a linear control law. With this observation in mind, the closed-loop system takes the form:

$$
\dot{\mathrm{x}}=\left(\tilde{\mathrm{A}}-\tilde{\mathrm{B}}_{2} \mathrm{~K}_{\mathrm{LQR}}\right) \mathrm{x}
$$

And the cost function $\mathrm{J}$ takes the form:

$$
\begin{gathered}
J=\int_{0}^{\infty} x(t)^{T} Q x(t)+\left(-K_{L Q R} x(t)\right)^{T} R\left(-K_{L Q R} x(t)\right) d t(29) \\
J=\int_{0}^{\infty} x(t)^{T}\left(Q+K^{T} R K_{L Q R}\right) x(t) d t
\end{gathered}
$$

The designed state feedback controller gain for both $\mathrm{LQR}$ and proposed controller must fulfil the following specifications:
- Settling time of $<3 \mathrm{sec}$ with overshoot $<1 \%$ and zero steady state error for the hub angle of the arm

- Sway motion is $< \pm 5$ degree

- Control input does not exceed $\pm 5 \mathrm{mV}$

\section{RESULTS AND DISCUSSION}

Applying the LMI conditions in Eq. 23-26, the parameter of conic sectors and disk that fulfil the design requirement is at $\lambda=-3, \mathrm{r}=5$ and $\theta=30^{\circ}$. Then, the state feedback gain, $\mathrm{K}$ is obtained as:

$$
\mathrm{K}=\left[\begin{array}{lllll}
-0.0057 & 0.0340 & -0.0015 & 0.0018 & 0.0051
\end{array}\right]
$$

with $\gamma=15.9616$. This state feedback gain also guarantees the $\mathrm{H}_{\mathrm{s}}$ performance $\left\|\mathrm{G}_{\mathrm{yw}}\right\|_{\mathrm{o}}<\gamma$. On the other hand, using lqr function in Matlab, the controller gain, $\mathrm{K}_{\mathrm{LQR}}$ for $\mathrm{LQR}$ is obtained as:

$$
\mathrm{K}_{\mathrm{LQR}}=\left[\begin{array}{lllll}
7.655 & -10.5154 & 1.5407 & 1.4648 & -14.1421
\end{array}\right]
$$

with $\mathrm{R}=1$ and;

$$
Q=\left[\begin{array}{ccccc}
15 & 0 & 0 & 0 & 0 \\
0 & 1 & 0 & 0 & 0 \\
0 & 0 & 1 & 0 & 0 \\
0 & 0 & 0 & 5 & 0 \\
0 & 0 & 0 & 0 & 200
\end{array}\right]
$$

Figure 5 shows that the location of poles has been confined in the selected LMI region. The response of hub angle of the arm, sway pendulum angle and control input are shown in Fig. 6-8 for both proposed and LQR controller. It shows that both controller can track the desired trajectory input with zero steady state error and achieve zero sway angle of the pendulum. Hence, in

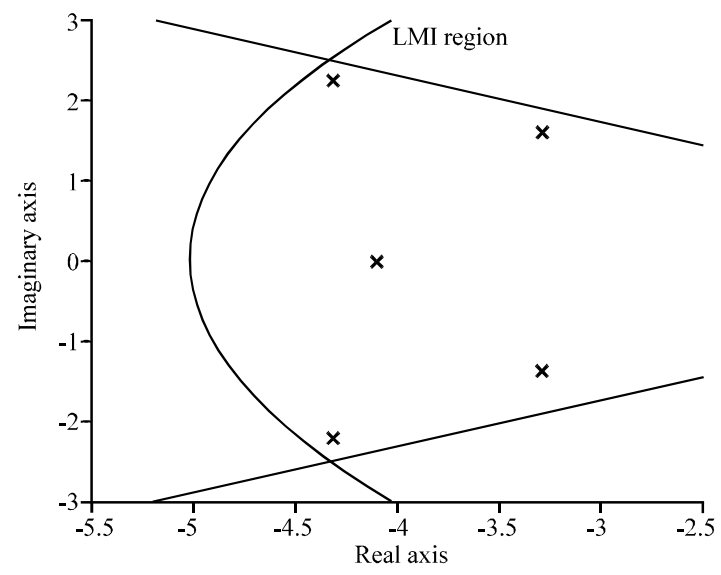

Fig. 5: Location of poles in selected LMI region 


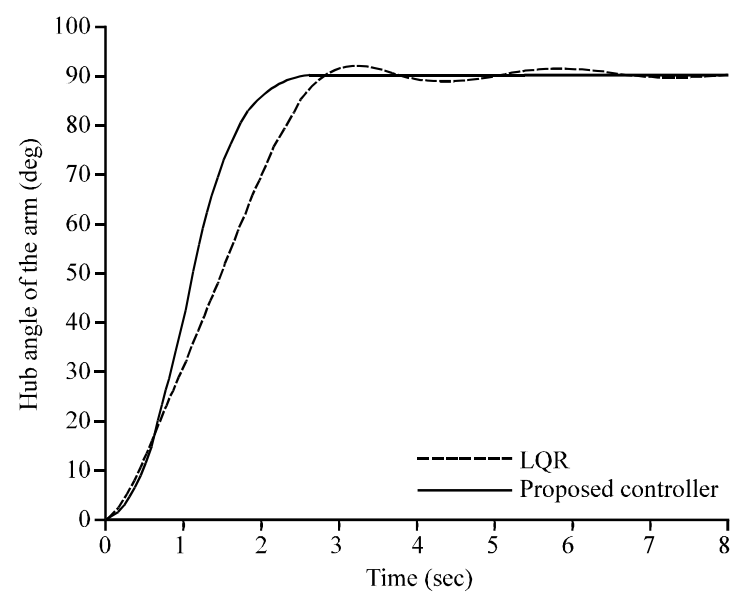

Fig. 6: Hub angle of the arm response

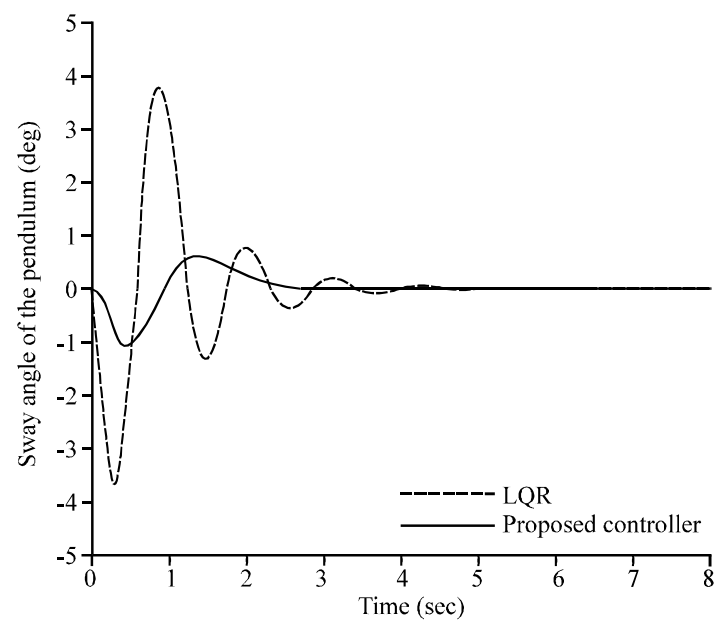

Fig. 7: Sway angle of the pendulum response

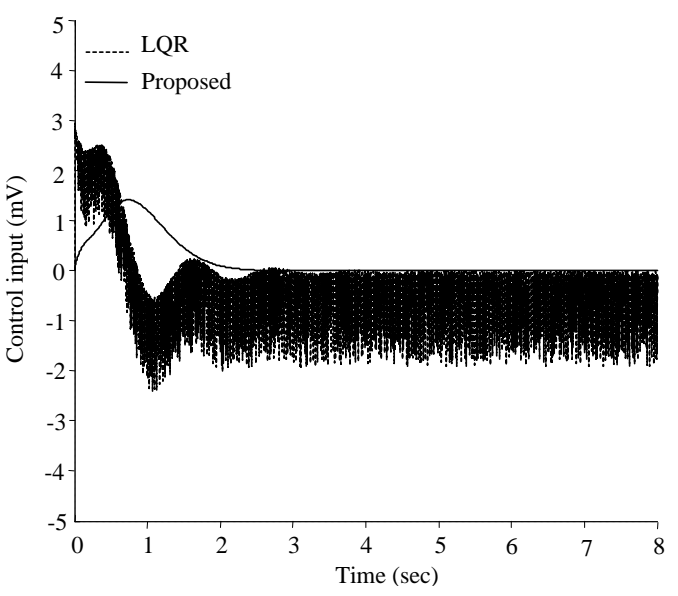

Fig. 8: Control input response

overall both controllers successfully fulfil the design requirement. However, the proposed controller produces a fast settling time with very minimal overshoot as compared to LQR controller. In addition, the proposed controller also shows a very minimal sway angle oscillation as compared to LQR controller. In terms of control input response, the proposed controller is better than LQR because it exhibits a very smooth and small input energy which is good for the lifetime of dc motor.

\section{CONCLUSION}

The development of $\mathrm{H}$-infinity controller based on LMI region schemes has been developed for rotary pendulum crane system. The results show that by confining the closed-loop poles of the rotary crane pendulum system based on LMI region, one can successfully achieve the desired specifications and the designed state feedback gain also guarantees the $\mathrm{H}$-infinity performance. The effectiveness of the proposed scheme has been compared with LQR controller. Particularly, the proposed controller has produced a fast input tracking capability with low input energy and minimal sway angle than $\mathrm{LQR}$ controller.

\section{ACKNOWLEDGEMENTS}

This research was supported by Faculty of Electrical and Electronics Engineering, Universiti Malaysia Pahang, especially Control and Instrumentation (COINS) Research Group and Ministry of Science, Technology and Innovation (MOSTI) under Research Grant Scheme RDU110374 and RDU100384.

\section{REFERENCES}

Ahmad, M.A., R.M.T. Raja Ismail, M.S. Ramli, N.F. Zakaria and N.M. Abd Ghani, 2009a. Robust feed-forward schemes for anti-sway control of rotary crane. Proceedings of the International Conference on Computational Intelligence, Modelling and Simulation, Septtember 7-9, 2009, IEEE Computer Society, Washington, DC, USA., pp: 17-22.

Ahmad, M.A., R.M.T.R. Ismail, M.S. Ramli, A.N.K. Nasir and N. Hambali, 2009b. Feed-forward techniques for sway suppression in a double-pendulum-type overhead crane. Int. Conf. Comp. Technol. Dev., 1: 173-178.

Ahmad, M.A., M.S. Ramli and R.M.T.R. Ismail, 2010a. Infinite impulse response filter techniques for sway control of a lab-scaled rotary crane system. Int. Conf. Comput. Model. Simul., 2: 192-196. 
Ahmad, M.A., M.S. Ramli, M.A. Zawawi and R.M.T.R. Ismail, $2010 \mathrm{~b}$. Hybrid collocated PD with non-collocated PID for sway control of a lab-scaled rotary crane. Proceedings of the 5th IEEE Conference on Industrial Electronics and Applications, June 15-17, 2010, Taichung, Taiwan, pp: 707-711.

Ahmad, M.A., R.E. Samin and M.A. Zawawi, 2010c. Comparison of optimal and intelligent sway control for a lab-scale rotary crane system. Int. Conf. Comput. Eng. Appl., 1: 229-234.

Ahmad, M.A., M.S. Saealal, M.A. Zawawi, R.M.T. Raja Ismail, 2011. Classical angular tracking and intelligent anti-sway control for rotary crane system. Proceedings of the International Conference on Electrical, Control and Computer Engineering, June 21-22, 2011, Kuantan, Malaysia, pp: 82-87.

Belanger, P., 1995. Control Engineering: A Modern Approach. Saunders College Publishing, Philadelphia, PA, USA., ISBN: 9780030134890 , Pages: 471.

Blackburn, D., J. Lawrence, J. Danielson, W. Singhose, T. Kamoi and A. Taura, 2010. Radial-motion assisted command shapers for nonlinear tower crane rotational slewing. Control Eng. Practice, 18: 523-531.
Boyd, S., L. El-Ghaoui, E. Feron and V. Balakrishnan, 1994. Linear Matrix Inequalities in System Control Theory. Vol. 15, SIAM, Philadelphia, PA, USA.

Chilali, M. and P. Gahinet, 1996. H8 design with pole placement constraints: An LMI approach. IEEE Trans. Autom. Control, 41: 358-367.

Chilali, M., P. Gahinet and P. Apkarian, 1999. Robust pole placement in LMI regions. IEEE Trans. Autom. Control, 44: 2257-2270.

Gahinet, P. and P. Apkarian, 1993. A linear matrix inequality approach to $\mathrm{H} 8$ control. Int. J. Robust Nonlinear Control, 4: 421-448.

Iwasaki, T. and R.E. Skelton, 1994. All controllers for the general H8 control problem: LMI existence conditions and state-space formulas. Automatica, 30: 1307-1317.

Packard, A., 1994. Gain scheduling via linear fractional transformations. Syst. Control Lett., 22: 79-92.

Vaughan, J., E. Maleki and W. Singhose, 2010. Advantages of using command shaping over feedback for crane control. Proceedings of the American Control Conference, June 30-July 2, 2010, Baltimore, USA., pp: 2308-2313. 